\title{
Using the Fasting Blood Sugar and Glycated Haemoglobin Models for Predicting the Personal Management of Type-2 Diabetes
}

\author{
Tahira Fulazzaky and Mohamad A Fulazzaky
}

\begin{abstract}
Purpose: Personal management of type-2 diabetes mellitus (T2DM) is very important in preventing complications of other diseases for infected patients. We aimed to develop the mathematical models for predicting the performance of personal T2DM management.

Methods: We proposed three hypotheses as the basic principles to develop the fasting blood sugar (FBS) and glycated haemoglobin (HbA1c) models. We tested and validated these two models using the FBS and HbA1c data collected from two clinical laboratories in Malaysia and one clinical laboratory in Indonesia from 16 March 2009 to 29 May 2016.

Results: Using the power FBS model permits us to predict the FBS level of below $6 \mathrm{mmol} / \mathrm{L}$ after 1277 days of the T2DM management. Using the logarithmic HbA1c model permits to predict the HbA1c level in blood of below $6.4 \%$ after 2553 days of the T2DM management but never reaches below $6 \%$. We verified that correlation between the FBS and HbA1c data is able to get an excellent fit with linear regression.

Conclusions: Person with T2DM can set goals for managing his disease and lifetime metabolic control to get better healthrelated quality of life (HRQoL) and should pay attention to the main determinants of HRQoL. Using the FBS and HbA1c models as strategic analysis tool permits us to predict the effectiveness of T2DM management with an ultimate improvement in his quality of life to take care of himself.
\end{abstract}

Index Terms - Diabetes self-management; Fasting blood sugar; HbA1c; Mathematical model; Type-2 diabetes mellitus.

\section{INTRODUCTION}

Despite of the prevalence of diabetes among people aged 20 - 79 years in Indonesia was recorded to be around 4.8\% for the year 2012 [1], the rising risk of diabetes is mostly due to the population growth, aging, urbanization, and increased prevalence of physical inactivity and obesity [2]. Since approximately 10 million cases of diabetes have been reported in 2015, Indonesia is becoming the seventh largest number of diabetic patients in the world [3]. Type-2 diabetes mellitus (T2DM) has been considered as a complex and serious chronic disease to impose a significant burden on the patients [4]. In the long term, people with diabetes have to

Published on November 27, 2019.

T. Fulazzaky is with the Faculty of Public Health, University of Indonesia, Depok 16424, Indonesia.

(e-mail: tahira.fulazzaky@ui.ac.id)

M. A. Fulazzaky is with the Department for Management of Science and Technology Development, Ton Duc Thang University, Ho Chi Minh City,

Vietnam and the Faculty of Environment and Labour Safety, Ton Duc

Thang University, Ho Chi Minh City, Vietnam.

(e-mail: mohamad.ali.fulazzaky@tdtu.edu.vn) face many complications if they are without care of good metabolic control [5]. In addition to diabetes-related complications, depression, hypoglycemic episodes, fear of hypoglycemia, and change in lifestyle are most related to decrease the health-related quality of life (HRQoL) [6]; therefore, the remission of T2DM would be a practical target for primary care [7]. It has been reported that HRQoL of person is associated with age, gender, economic development, education, and marital status [8]. It emerges that HRQoL and treatment satisfaction are both influenced by socio-demographic and clinical characteristics while the HRQoL of T2DM patient can be improved by receiving more attention in his health and economic status [9]. Effect of lifestyle intervention on HRQoL is the most important consideration in the management of T2DM [10] due to the microvascular and macrovascular complications and associated non-vascular comorbidity can substantially decrease the HRQoL of diabetic patient [11-14]. The best defense against complications of T2DM is to take a good care of the lifetime metabolic control by maintaining the normal blood sugar levels of 4.0 to $6.0 \mathrm{mmol} / \mathrm{L}$, keeping active, and making healthy choices [15].

Many mathematical models of engineering systems have been proposed for standard calculation techniques in the study of the corrosion penetration rate of titanium base materials materials [16], the determination of the resistance of mass transfer $[17,18]$, the assessment of the optimal retention time of bio-trickling filter reactor [19], the design of bio-sand filtration [20], the calculation of the accumulation rate, lifetime, and adsorption capacity for the adsorption of oil and grease [21], and other engineering activities [22,23]. However, the development of mathematical models in the field of medicine and health is still rare and is a growing area of specialisation [24,25]. Mathematical models of modelling the medical data can take many forms particularly to statistical models. Even though one of the most intriguing fields of research for modelling the medical data is the interaction between diabetes and depression [26,27], the personal experience of managing the T2DM by translating the intensive lifestyle intervention is still not fully disclosed. Only a limited number of studies have been carried out to establish the empirical models for investigating the HRQoL of diabetic patients in Indonesia even though this country has been ranked seventh among the first ten countries with the largest number of reported cases of diabetes [3]. The establishment of a correlation between fasting blood sugar (FBS) and glycated haemoglobin (HbAlc) should be consistent with the clinical data of diabetic patient and can be verified 
during the present study. The objectives of this study are: (1) to develop the empirical models for predicting the level of $\mathrm{HbAlc}$ in the blood based on the FBS value after ten years experience of managing T2DM for the person living with type-2 diabetes, (2) to identify the situations where personal safety is at risk and outlining ways to reduce the risk of diabetes-related complications to be predicted using the FBS and HbA1c models, and (3) to share the personal experience of managing the T2DM with other people that intend to improve the HRQoL among the T2DM patients.

\section{MEthods}

\section{A. Data Collection}

This study used the personal diabetes-related health data collected from three different clinical laboratories, i.e., (1) the Health Center Laboratory of Universiti Tun Hussein Onn Malaysia (UTHM) at Batu Pahat, Johor state of Malaysia, collected from 16 March 2009 to 1 December 2010, (2) the Health Center Laboratory of Universiti Teknolgi Malaysia (UTM) at Johor Bahru, Johor state of Malaysia, collected from 13 April 2011 to 29 May 2016, and (3) the Clinical Laboratory of Mulia Hospital (MH) at Bogor, West Java province of Indonesia, collected from 3 July 2017 to 20 December 2017. The personal experience of managing the T2DM was discussed with the analysis focused on the variations of FBS and HbAlc over the period of 9 years. Ancillary data sets of cholesterol HDL, cholesterol LDL, triglyceride, and uric acid for assessing the probabilities of positive and negative experiences were associated with the prevalence and incidence of physical health to support the personal clinical data.

\section{B. Measurements of FBS and $\mathrm{HbAlc}$}

Level of FBS in the blood was periodically measured using the glucometer (Accu-Chek, Roche Diabetes Care Deutschland $\mathrm{GmbH}$, Germany). In spite of four basic types of the analytical methods i.e., ion-exchange highperformance liquid chromatography (HPLC), boronate affinity HPLC, immunoassay, and enzymatic assays are commonly used for the measurement of HbAlc [28], the levels of $\mathrm{HbAlc}$ in blood were measured periodically with the method of ion-exchange HPLC (Menarini-Arkray Analyzer HA-8160, Kyoto, Japan) in two health center laboratories of UTHM and UTM and with the method of boronate affinity HPLC (Epithod $\AA$ 616, DxGen Corp, Gyeonggi-do, Korea) in the clinical laboratory of $\mathrm{MH}$.

\section{Hypotheses}

The development of the FBS and HbA1c models systematically adheres each with two parameters. Physical meanings of every parameter must be verified to describe the determinant of lifestyle behaviour of the T2DM patient. The FBS and HbA1c models were developed based on three hypotheses, such that: (1) the FBS level of person with T2DM can be managed by keeping active and making healthy choices over time due to the body of a non-acute onset of diabetes is able to lower the level of sugar in blood, (2) the level of FBS would powerly decrease to reach a satisfactory condition of below $6 \mathrm{mmol} / \mathrm{L}$ due to regular physical activity and medical nutrition therapy can regulate healthcare, while synthetic or human insulin lowers blood sugar by helping the cells to use glucose, that the glucose can go through metabolic pathways to be broken down for energy or stored it for later use, and (3) the physical activity and medical nutrition therapy can logarithmically decrease the value of $\mathrm{HbA} 1 \mathrm{c}$ in blood of person with T2DM to reach satisfactory condition while in people who do not have diabetes the HbA1c value is usually below $6 \%$.

\section{Models Development}

The dependent variables for the development of the FBS model are limited to the FBS and time passed to measure the FBS level in blood. Establishing the FBS model focused on the variability of FBS as a function of time is due to the effectiveness of physical activity and medical nutrition therapy affects the FBS levels. The development of FBS model was based on the hypotheses $(1,2)$ dealing with time series data of 84 times of the FBS measurement during the period from 16 March 2009 to 20 December 2017. The FBS model can be suggested in the form of power function:

$F=a t^{(b)}$

where $F$ is the FBS concentration (in $\mathrm{mmol} / \mathrm{L}$ ), $a$ is the decreased FBS rate coefficient (in $\mathrm{mmol} / \mathrm{L} \mathrm{d}$ ), $t$ is the time passed to measure the FBS level in blood (in d), and $b$ is the diabetes-related power model constant (dimensionless).

The dependent variables for the development of the HbA1c model are limited to the HbAlc and time passed to measure the HbA1c level in blood. The HbA1c model was developed based on the hypotheses $(1,3)$ dealing with time series data of 14 times of the HbAlc measurement during the period from 17 March 2009 to 15 April 2017. Establishing the HbAlc model only focused on the variability of $\mathrm{HbAlc}$ as a function of time is due the effective management of T2DM can be verified by monitoring the level of HbAlc in blood and is of main concern with the T2DM patients. The HbA1c model can be suggested in the form of logarithmic function:

$H=m[\ln (t)]+n$

where $H$ is the HbAlc level in blood (in \%), $m$ is the decreased HbAlc rate coefficient (in $\% / d$ ), $t$ is the time passed to measure the HbA1c level in blood (in d), and $n$ is the diabetes-related logarithmic model constant (in \%).

Combining Eq. (1) with Eq. (2) yields the following equation:

$H=m\left(\frac{\ln (F)-\ln (a)}{b}\right)+n=\frac{m[\ln (F)]}{b}+\frac{m[\ln (a)]}{b}+n$

Then Eq. (3) can be written in the simplest form of:

$H=c[\ln (F)]+d$

with $c=\frac{m}{b}$ is the HbAlc - FBS correlation coefficient (in \% $\mathrm{L} / \mathrm{mmol})$ and $d=\frac{m[\ln (a)]}{b}+n$ is the constant relating correlation between the HbA1c and FBS data (in \%). 


\section{RESULTS}

\section{A. Fasting Blood Sugar Model}

A plot (Fig. 1a) of $F$ versus $t$ yields a shape of the power line as it has been suggested by Eq. (1) and provides the mathematical expression of $F=16.185 t^{(-0.141)}$ where $a$ equals $16.185 \mathrm{mmol} / \mathrm{L} \mathrm{d}$ and $b$ equals -0.141 . Regression analysis of the power fitting curve shows a good agreement with the FBS data with $R^{2}=0.72065$ (see Table 1). A zigzag pattern around the regression line is due to the mismanagement of T2DM in regulating the safe practice of physical activity and the effectiveness of medical nutrition therapy.

(a)

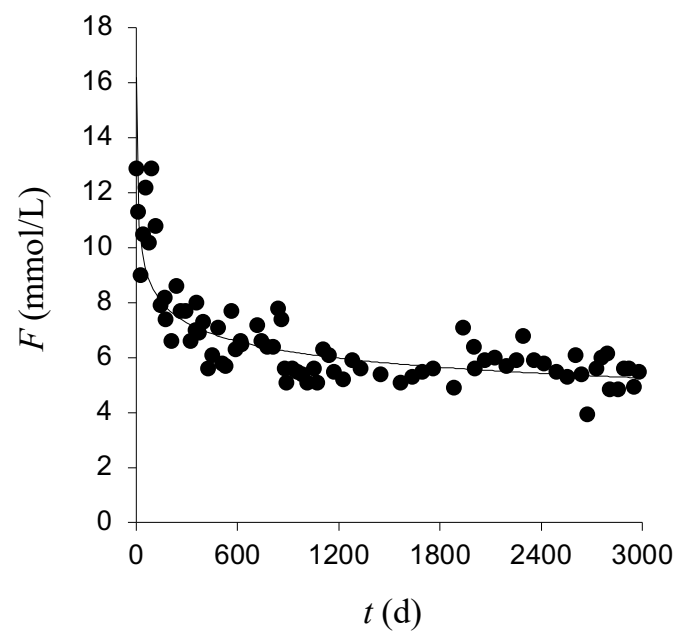

(b)

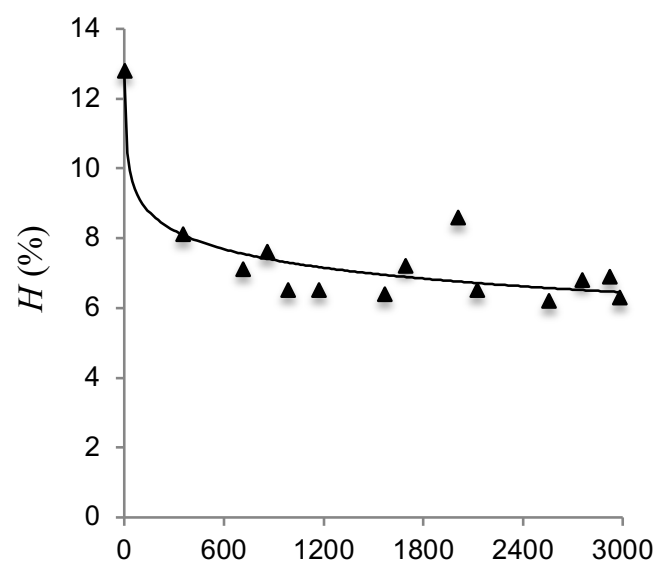

$t(\mathrm{~d})$

Fig. 1. Results of the personal experience of managing the T2DM with (a) the variation of FBS over time and (b) the variation of $\mathrm{HbAlc}$ over time.

TABLE I: VALUE OF THE PARAMETERS IN EQUATIONS

\begin{tabular}{|c|c|c|c|}
\hline Model & \multicolumn{2}{|c|}{$\begin{array}{l}\text { Parameters in equations } \\
\qquad(a, b, m . n, c, d)\end{array}$} & $R^{2}$ \\
\hline Power FBS model & $\begin{array}{l}a=16.185 \mathrm{mmol} \mathrm{L}^{-1} \\
\mathrm{~d}^{-1}\end{array}$ & $b=0.141$ & 0.72065 \\
\hline $\begin{array}{l}\text { Logarithmic } \\
\text { HbA1c model }\end{array}$ & $\begin{array}{l}m=-4.3 \mathrm{mmol} \mathrm{mol} \mathrm{mol}^{-1} \\
\mathrm{~d}^{-1}\left(-0.77 \% \mathrm{~d}^{-1}\right)\end{array}$ & $\begin{array}{l}n=91.4 \\
\mathrm{mmol} \mathrm{mol}^{-1} \\
(12.6 \%)\end{array}$ & 0.85109 \\
\hline $\begin{array}{l}\text { Linear correlation } \\
\text { of the FBS to } \\
\text { HbAlc data }\end{array}$ & $\begin{array}{l}c=39.59 \mathrm{~L} \mathrm{~mol}^{-1} \\
\left(5.46 \% \mathrm{~L} \mathrm{mmol}^{-1}\right)\end{array}$ & $\begin{array}{l}d=18.78 \\
\mathrm{mmol} \mathrm{mol}^{-1} \\
(-2.59 \%)\end{array}$ & 1.00000 \\
\hline
\end{tabular}

\section{B. Glycated Haemoglobin Model}

A plot (Fig. 1b) of $H$ versus $t$ according to Eq. (2) yields a shape of the logarithmic line and gives the mathematical expression of $H=-0.77 \ln (t)+12.6$ where $m$ equals $0.77 \% / \mathrm{d}$ and $n$ equals $12.6 \%$. Regression analysis of the logarithmic fitting curve shows a good agreement with the HbAlc data with $R^{2}=0.85109$ (see Table 1 ). The variations of $\mathrm{HbAlc}$ around the regression line occur due to the changes in patterns of physical activity and medical nutrition therapy conditioned to feel a lack of the control are more likely to see that the normal HbA1c pattern does not exist particularly for one point just at $2007^{\text {th }}$ day of measuring the HbAlc level in blood.

\section{Correlation between the FBS and HbAlc Data}

Decreasing two curves of modelling $F$ versus $t$ and $H$ versus $t$ is very similar to each other even though the FBS model is expressed in the form of power function and the HbAlc model is expressed in the form of ogarithmic function (see Fig. 2a). In spite of the FBS can reach 5.98 mmol/L after 1169 days (see Fig. 2a, line-(i)), the level of HbA1c in blood can never reach 6\% even after 2979 days of the T2DM management (see Fig. 2a, line-(ii)). By plotting the curve of $H$ versus $\ln (F)$ as suggested in Eq. (4) yields a shape of the linear line with the mathematical expression of $H=5.46 \ln (F)-2.59$ where $c$ equals $5.46 \% \mathrm{~L} / \mathrm{mmol}$ and $d$ equals $-2.59 \%$ (Fig. 2b). Linear regression analysis provides an excellent correlation between the FBS and HbA1c data with $R^{2}=1.00000$ (see Table 1). Empirical evidence (Fig. $2 \mathrm{~b})$ shows that the level of HbAlc in blood varies over time and is proportionally dependent on the FBS value.

(a)

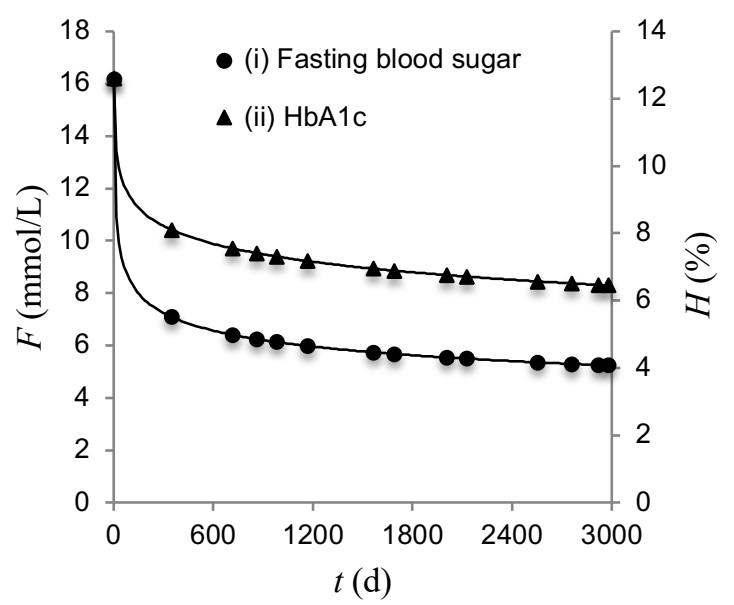

(b) 


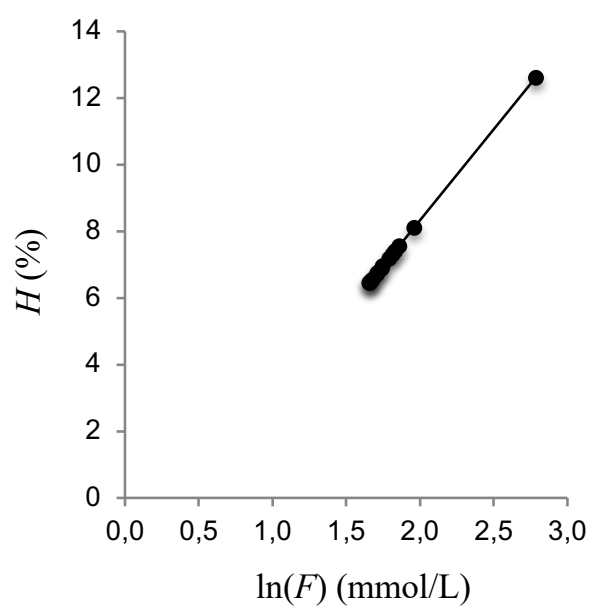

Fig. 2. Results of modelling the FBS and HbA1c data with (a) the curve of modelling (i) $F$ versus $t$ and (ii) $H$ versus $t$ and (b) the correlation between the FBS and HbAlc data.

\section{Discussion}

The limitations of this study may relate to the diabetesrelated health data collected from the personal health record of only one person with type- 2 diabetes. The clinical HbAlc data collected from the periodical measurements of blood using three different equipments were based on the examinations carried out by different medical analysts from two health center laboratories in Malaysia and one clinical laboratory in Indonesia. In spite of the FBS data have been recorded using the personal computer during 3223 days of the T2DM management from March 2009 to December 2017 (see Fig. 1a), the personal experience of living with T2DM is estimated to have been since at least 2004 due to the early signs and symptoms of T2DM have been gradual over the last few years. This has been attributed to the fact that an incidence of the T2DM is not immediately aware by an infected person but can lead to disparities in the level of physical activity carried out and consequently to disparities in the levels of health [29]. The results (Fig. 1a) of monitoring the FBS levels during approximately 3300 days show a decreased power trendline of blood sugar to normal blood sugar levels of below $6 \mathrm{mmol} / \mathrm{L}$ after 1277 days of the T2DM management. This is due to the entire set of healthy diet, physical activity, and the use of medicine have long been a fundamental component of the personal experience to lower the sugar level in blood [30]. The personal management of T2DM has been experienced in several periods, i.e., (1) by diet without use of medicine from March to June 2009, (2) by orally taking one tablet of metformin hydrochloride $500 \mathrm{mg}$ per day from June to September 2009, (3) by orally taking two 500-mg metformin tablets per day from October 2009 to March 2010, (4) by orally taking three 500-mg metformin tablets per day from April 2010 to October 2011, (5) by orally taking two 500-mg metformin tablets plus one tablet of gliclazide $80 \mathrm{mg}$ from November 2011 to January 2017, and (6) by orally taking two 500-mg metformin tablets plus one $60-\mathrm{mg}$ gliclazide table from February 2017 to December 2017. In the latest period, the use of medicine was optimised by orally taking one tablet of acetylsalicylic acid $80 \mathrm{mg}$ as blood thinner and one tablet of Vitamin B1 $50 \mathrm{mg}$ per day, which is essential for glucose metabolism and healthy nerve, muscle, and heart function. Contribution of regular physical activity to the T2DM management has been experienced with playing tennis three times per week from March 2009 to December 2010, two times per week from January 2011 to May 2016, and one time per week from June 2016 to December 2017. The personal experience has never been about getting foods and drinks with added sugar since 2009 in spite of drinking coffee and tea has been linked to a lower risk for diabetes [30]. A previous study has noted that sugar consumption can increase in proportion to intake of other nutrients when obesity begins to increase substantially [31]. It has been reported small different trends between FBS and non-fasting blood sugar (NFBS) levels [32], which would be a sufficient basis to be considered further, that this innovative approach can be used to model the HbAlc data in the same way for the assessment of the NFBS levels.

Figure $1 \mathrm{~b}$ shows a decreased logarithmic trendline of the HbA1c to a level nearly $6 \%$ after 2553 days of the T2DM management. Better outcomes may relate to the less fluctuation of $\mathrm{HbA1c}$ value in blood [33]. An increase in the HbAlc of $8.6 \%$ just on the $2007^{\text {th }}$ day of the T2DM management was due to direct experience in fasting during the holy month of Ramadan affected personal behaviour change with an uncontrollable urge to eat a larger quantity of the foods can lead to an increase of the HbAlc level in the blood. An elevated HbAlc level in the blood revealed that the interference with some types of meals consumed can maintain at a high level of sugar about three months in the blood [34]. Lack of participation in the physical activity during the month of Ramadan tends to be able to contribute to a greater risk for diabetic patients due to the regular physical activity is the most important influence in supporting the effectiveness of T2DM management [34]. Since the FBS data can be modelled by power function (see Fig. 1a) and the HbAlc data by logarithmic function (see Fig. 1b), this may allow us to compare the trendlines of FBS to HbAlc in one figure (see Fig. 2a). Therefore, it is interesting to analyse on what factors can affect the improvement of HRQoL based on the personal T2DM management $[35,36]$.

The art of modelling the FBS and HbAlc data as an innovative approach lies in the appropriate simplification and abstraction of a set of data collected from the medical examination of a person with T2DM by defined procedure $[37,38]$. Both powerly decreasing function of the FBS curve and logarithmically decreasing function of the HbAlc curve (see Fig. 2a, lines-(i, ii)) clearly showed that the management of T2DM by keeping active and making healthy choices can influence sugar level in the blood and improves the HRQoL of T2DM patient. Empirical evidence (Fig. 2a) showed that decreasing trend of the FBS and $\mathrm{HbA} 1 \mathrm{c}$ curves is very similar to each other and reveals a successful T2DM self-management in lowering the blood sugar levels [5]. These two curves can be represented as a single curve by considering a step-by-step improvement of HRQoL. Using the power FBS model permits us to predict that an optimal management of T2DM can lower the blood sugar levels to below $6 \mathrm{mmol} / \mathrm{L}$ after 1169 days (see Fig. 2a; line-(i)). Using the logarithmic HbA1c model permits us to assess an optimal management of T2DM for lowering the level of HbA1c in blood to approximately $6.45 \%$ in spite of it never reaches below than $6 \%$ even after 2979 days of the T2DM management (see Fig. 2a; line-(ii)). The improvement of HRQoL is supported by the assessment of clinical data collected from March 2009 to March 2016 to 
show that the levels of cholesterol HDL of higher than 0.9 $\mathrm{mmol} / \mathrm{L}$, cholesterol LDL of lower than $4 \mathrm{mmol} / \mathrm{L}$, triglyceride of lower than $1.9 \mathrm{mmol} / \mathrm{L}$, and uric acid in the range of 202 to $416 \mathrm{mmol} / \mathrm{L}$ are in the normal values of all metabolic parameters (see Table 2). By considering the normal range for $\mathrm{HbAlc}$ levels is between 4 and $5.6 \%$ for people without diabetes, the HbA1c levels between 5.7 and $6.4 \%$ mean that people have a higher change of getting diabetes, and the HbA1c levels of $6.5 \%$ or higher mean that people have diabetes [39-41]. The optimal management of T2DM requires vigilant awareness of maintaining active and eating healthy foods that some diabetic patients may go into remission even though there is no diabetes cure $[42,43]$. Due to both the curves of $F$ versus $t$ and $H$ versus $t$ show a very similar trend (see Fig. 2a), the correlation between the $\mathrm{HbA1c}$ and FBS data can assess the personal experience of managing T2DM. Even though it has been reported a close relationship between the $\mathrm{HbA} 1 \mathrm{c}$ and mean blood sugar data [44], the use of Eqs. $(1,2)$ affected by many factors may limit the usefulness and applicability of a unique mathematical model to all diabetes patients. The patient variables of gender, age, and race may affect the fluctuation of FBS and HbAlc in blood [45], leading to different trendlines of the power FBS and logarithmic HbA1c models, which can significantly affect the personal T2DM management.

TABLE 2: RESULTS OF MONITORING CHOLESTEROL DHL, CHOESTEROL LDH, TRIGLYCERIDE AND URIC ACID

\begin{tabular}{lllll}
\hline \multicolumn{5}{c}{ LDH, TRIGLYCERIDE AND URIC ACID } \\
Date & $\begin{array}{l}\text { Cholester } \\
\text { ol HDL }\end{array}$ & $\begin{array}{l}\text { Cholester } \\
\text { ol LDL }\end{array}$ & $\begin{array}{l}\text { Triglycer } \\
\text { ide }\end{array}$ & Uric acid \\
\hline Unit & $\mathrm{mmol} \mathrm{L}^{-1}$ & $\mathrm{mmol} \mathrm{L}^{-1}$ & $\mathrm{mmol} \mathrm{L}^{-1}$ & $\mathrm{mmol} \mathrm{L}^{-1}$ \\
\hline Normal range & $>0.9$ & $<4$ & $<1.9$ & $202-416$ \\
\hline 17 March 2009 & 1.36 & 2.7 & - & 181 \\
03 March 2010 & 1.33 & 2.3 & - & 222 \\
13 April 2011 & 1.40 & 2.4 & 0.6 & - \\
20 September 2011 & 1.20 & 2.5 & 0.9 & - \\
20 January 2012 & 1.20 & 2.2 & 0.9 & 219 \\
09 May 2013 & 1.50 & 2.3 & 0.8 & 304 \\
22 September 2014 & 1.40 & 2.4 & 1.0 & 273 \\
18 January 2015 & 1.40 & 2.4 & - & 255 \\
06 March 2016 & 1.20 & 2.3 & 0.9 & 265 \\
\hline \hline
\end{tabular}

A linear regression analysis of plotting $H$ versus $\ln (F)$ provides an excellent fit to data set with $R^{2}=1.00000$ (see Fig. 2b; see also Table 1). Meaning that the use of the parameters in Eq. (4) is useful to predict the HbAlc level in blood since the FBS value has been checked medically. Using Eq. (4) permits us to predict the HbA1c value in blood of the T2DM patients in spite of the accuracy of the $\mathrm{HbA} 1 \mathrm{c}$ prediction is dependent on both the personal T2DM management and T2DM linked to a host of other health problems $[46,47]$. As a result, the process modelling with the FBS and HbAlc data as a rapid appraisal of the management of diabetes [48] is looking for ways to reduce costs associated with the medical examinations without sacrificing the required amount of the blood drawn or making the lives of T2DM patients more difficult. Learning about the application of linear equation: $H=5.46 \ln (F)$ 2.59 gives a new insight on the improvement of HRQoL for the T2DM patients and is algebra helpful in solving real life problems of the personal T2DM management for avoiding a worsening glycemic control that leads to the increased risk of an increase in the score of Diabetes Complications
Severity Index [49,50]. We expect that the results of this study may increase healthcare awareness of T2DM patients and help person with T2DM in overcoming the barriers that delay insulin treatment $[51,52]$. In this work, we can assess the awareness of a person living with T2DM by modelling his personal FBS and $\mathrm{HbAlc}$ data to reflect on the language of diabetes and share insights with other T2DM patients [53] for the improvement of HRQoL of people undergoing sugar lowering therapy.

\section{Conclusions}

In this study, the development of the FBS and the HbAlc models to predict the effectiveness of personal T2DM management was based on three hypotheses. Using the FBS model permits us to predict trends and fluctuations of FBS value for a diabetic patient continuously decreasing over time to reach a satisfactory condition of below $6 \mathrm{mmol} / \mathrm{L}$. Using the HbAlc model permits us to predict trends and fluctuations of $\mathrm{HbAlc}$ level continuously decreasing over time to reach $6.45 \%$ but never below $6 \%$. The linear regression analysis provides an excellent correlation of the FBS to HbAlc data to possibly determine the level of HbAlc in blood based on the FBS value. The need for better personal management of T2DM may improve the HRQoL of T2DM patient, which can be optimised by keeping active and making healthy choices. Challenges to improve the HRQoL of diabetic patient are revealed using the empirical models of the personal T2DM management to contribute to the future directions for efficient problem-solving ability of the T2DM management with aim to share with other people.

\section{ACKNOWLEDGMENT}

The authors would like to thank kindly all participants in the study from the Health Center Laboratory of UTHM at Batu Pahat of Johor state in Malaysia, the Health Center Laboratory of UTM at Johor Bahru of Johor state in Malaysia, and the Clinical Laboratory of $\mathrm{MH}$ at Bogor of West Java province in Indonesia for providing their assistance in the data compilation.

\section{REFERENCES}

[1] P. Soewondo, A. Ferrario, D. L. Tahapary, "Challenges in diabetes management in Indonesia: a literature review," Global Health, vol. 9, no. 63 , Dec 2013.

[2] M. Javanbakht, F. Abolhasani, A. Mashayekhi, et al., "Health related quality of life in patients with type 2 diabetes mellitus in Iran: A national survey," PLoS One, vol. 7, no. 8, p. e44526, Aug 2012.

[3] M. -M. Sandu, D. C. Protasiewicz, A. G. Firănescu, et al., "Data regarding the prevalence and incidence of diabetes mellitus and prediabetes," Rom J Diabetes Nutr Metab Dis, vol. 23, no. 1, pp. 95103, Mar 2016.

[4] Y. Wu, Y. Ding, Y. Tanaka, et al., "Risk factors contributing to type 2 diabetes and recent advances in the treatment and prevention," Int $J$ Med Sci, vol. 11, no. 11, pp. 1185-1200, Sep 2014

[5] S. R. Shrivastava, P. S. Shrivastava, J. Ramasamy, "Role of self-care in management of diabetes mellitus," J Diabetes Metab Disord, vol. 12, no. 14, Mar 2013.

[6] D. J. Wexler, R. W. Grant, E. Wittenberg, et al., "Correlates of healthrelated quality of life in type 2 diabetes," Diabetologia, vol. 49 , no. 7 , pp. 1489-1497, Jul 2006.

[7] M. E. J. Lean, W. S. Leslie, A. C. Barnes, et al., "Primary care-led weight management for remission of type 2 diabetes (DiRECT): an open-label, cluster-randomised trial," Lancet, vol. 391, no. 10120, pp. 541-551, Feb 2018. 
[8] Y. Lu, N. Wang, Y. Chen, et al., "Health-related quality of life in type-2 diabetes patients: a cross-sectional study in East China," BMC Endocr Disord, vol. 17, no. 38, Jul 2017.

[9] S. H. Zyoud, S. W. Al-Jabi, W. M. Sweileh, et al., "Relationship of treatment satisfaction to health-related quality of life among Palestinian patients with type 2 diabetes mellitus: Findings from a cross-sectional study," J Clin Transl Endocrinol, vol. 2, no. 2, pp. 6671, Mar 2015.

[10] L. Chen, J. H. Pei, J. Kuang, et al., "Effect of lifestyle intervention in patients with type 2 diabetes: A meta-analysis," Metabolism, vol. 64 , no. 2, pp. 338-47, Feb 2015.

[11] W. T. Cade, "Diabetes-related microvascular and macrovascular diseases in the physical therapy setting," Phys Ther, vol. 88, no. 11, pp. 1322-1335, Nov 2008.

[12] M. J. Fowler, "Microvascular and macrovascular complications of diabetes," Clin Diabetes, vol. 26, no. 2, pp. 77-82, Apr 2008.

[13] J. M. Valderas, B. Starfield, B. Sibbald, et al., "Defining comorbidity: Implications for understanding health and health services," Ann Fam Med, vol. 7, no. 4, pp. 357-363, Jul-Aug 2009.

[14] P. E. Wändell, "Quality of life of patients with diabetes mellitus. An overview of research in primary health care in the Nordic countries," Scand J Prim Health Care, vol. 23, no. 2, pp. 68-74, Jun 2005.

[15] M. Asif, "The prevention and control the type-2 diabetes by changing lifestyle and dietary pattern," J Educ Health Promot, vol. 3, no. 1, Feb 2014.

[16] N. Ali, M. A. Fulazzaky, M. S. Mustapa, et al., "Assessment of fatigue and corrosion fatigue behaviours of the nitrogen ion implanted CpTi," Int J Fatigue, vol. 61, pp. 184-190, Apr 2014.

[17] M. A. Fulazzaky, "Determining the resistance of mass transfer for adsorption of the surfactant onto granular activated carbons from hydrodynamic column," Chem Eng J, vol. 166, no. 3, pp. 832-840, Feb 2011.

[18] M. A. Fulazzaky, M. H. Khamidun, R. Omar, "Understanding of mass transfer resistance for the adsorption of solute onto porous material from the modified mass transfer factor models," Chem Eng $J$, vol 228, pp. 1023-1029, Jul 2013.

[19] M. A. Fulazzaky, A. Talaiekhozani, T. Hadibarata, "Calculation of optimal gas retention time using a logarithmic equation applied to a bio-trickling filter reactor for formaldehyde removal from synthetic contaminated air," RSC Adv, vol. 3, no. 15, pp. 5100-5107, Feb 2013.

[20] M. A. Fulazzaky, N. M. Sunar, A. A. A. Latiff AAA, et al., "Empirical models of bio-sand filter to calculate the design parameters," Water Supply, vol. 9, no. 6, pp. 723-734, Dec 2009

[21] M. A. Fulazzaky, S. Abdullah, M. R. Salim, "Fundamentals of mass transfer and kinetics for biosorption of oil and grease from agro-food industrial effluent by Serratia marcescens SA30," RSC Adv, vol. 5, no. 127, pp. 104666-104673, Dec 2015.

[22] E, Antona, Mathematical Models and Their Use in Engineering. In: A. Miele, A. Salvetti (eds) Applied Mathematics in Aerospace Science and Engineering. Mathematical Concepts and Methods in Science and Engineering, Boston: Springer, 1994, vol 44, pp. 395-433.

[23] G. A. Hazelrigg, "On the role and use of mathematical models in engineering design," J Mech Des, vol. 121, no. 3, pp. 336-341, Sep 1999.

[24] B. I. Verma, S. K. Ray, R. N. Srivastava "Mathematical models and their applications in medicine and health," Health Popul Perspect Issues, vol. 4, no. 1, pp. 42-58, Jan-Mar 1981.

[25] R. B. Chambers, "The role of mathematical modeling in medical research: "research without patients?" Ochsner J, vol. 2, no. 4, pp. 218-223, Oct 2000

[26] A. Trikkalinou, A. K. Papazafiropoulou, A. Melidonis, "Type 2 diabetes and quality of life," World J Diabetes, vol. 8, no. 4, pp. 120129, Apr 2017.

[27] T. Xu, L. L. M. Hanson, T. Lange, et al., "Workplace bullying and violence as risk factors for type 2 diabetes: a multicohort study and meta-analysis," Diabetologia, vol. 61, no. 1, pp. 75-83, Jan 2018.

[28] R. R. Little, W. L. Roberts, "A review of variant hemoglobins interfering with hemoglobin A1c measurement," J Diabetes Sci Technol, vol. 3, no. 3, pp. 446-451, May 2009.

[29] J. Bolívar, A. Daponte, M. Rodríguez, et al., "The influence of individual, social and physical environment factors on physical activity in the adult population in Andalusia, Spain," Int $J$ Environ Res Public Health, vol. 7, no. 1, pp. 60-77, Jan 2010.

[30] M. B. Rise, A. Pellerud, L. Ø. Rygg, et al., "Making and maintaining lifestyle changes after participating in group based type 2 diabetes self-management educations: a qualitative study," PLoS One, vol. 8 , no. 5, pp. e64009, May 2013

[31] X. Guo, Y. Park, N. D. Freedman ND, et al., "Sweetened beverages, coffee, and tea and depression risk among older US adults," PLoS One, vol. 9, no. 4, pp. e94715, Apr 2014.
[32] S. Moebus, L. Göres, C. Lösch, et al., "Impact of time since last caloric intake on blood glucose levels," Eur J Epidemiol, vol. 26, no. 9, pp. 719-28, Sep 2011.

[33] Z. Z. Shen, Y. Y. Huang, C. J. Hsieh, "Early short-term intensive multidisciplinary diabetes care: A ten-year follow-up of outcomes," Diabetes Res Clin Pract, vol. 130, pp. 133-141, Aug 2017.

[34] R. Deng, "A review of the hypoglycemic effects of five commonly used herbal food supplements," Recent Pat Food Nutr Agric, vol. 4, no. 1, pp. 50-60, Aprl 2012.

[35] D. E. R. Warburton, C. W. Nicol, S. S. D. Bredin, "Health benefits of physical activity: the evidence," CMAJ, vol. 174 , no. 6 , pp. 801-809, Mar 2006

[36] C. Bitterlich, D. Vordermark, "Analysis of health-related quality of life in patients with brain tumors prior and subsequent to radiotherapy," Oncol Lett, vol. 14, no. 2, pp. 1841-1846, Aug 2017.

[37] B. Rushforth, C. McCrorie, L. Glidewell, et al., "Barriers to effective management of type 2 diabetes in primary care: qualitative systematic review," Br J Gen Pract, vol. 66, no. 643, pp. e114-27, Feb 2016.

[38] S. V. Edelman, W. H. Polonsky, "Type 2 diabetes in the real world: The elusive nature of glycemic control," Diabetes Care, vol. 40, no. 11, pp. 1425-32, Nov 2017.

[39] G. R. Spedding, "Comparing fluid mechanics models with experimental data," Philos Trans R Soc Lond B Biol Sci, vol. 358, no. 1437, pp. 1567-76, Sep 2003.

[40] Z. He, S. Carini, T. Hao, et al., "A method for analyzing commonalities in clinical trial target populations," AMIA Annu Symp Proc, vol. 2014, pp. 1777-1786, Nov 2014.

[41] S. I. Sherwani, H. A. Khan, A. Ekhzaimy A, et al., "Significance of HbA1c test in diagnosis and prognosis of diabetic patients," Biomark Insights, vol. 11, pp. 95-104, Jul 2016.

[42] E. Standl, "Does using HbAlc inform diagnosis of diabetes in patients with coronary artery disease?" Eur Heart J, vol. 36, no. 19, pp. 1149-1151, May 2015.

[43] J. B. Buse, S. Caprio, W. T. Cefalu, et al., "How do we define cure of diabetes?" Diabetes Care, vol. 32, no. 11, pp. 2133-5, Nov 2009.

[44] R. Taylor, "Pathogenesis of type 2 diabetes: tracing the reverse route from cure to cause," Diabetologia, vol. 51, no. 10, pp. 1781-1789, Oct 2008.

[45] K. Makris, L. Spanou, "Is there a relationship between mean blood glucose and glycated hemoglobin?" J Diabetes Sci Technol, vol. 5, no. 6 , pp. 1572-1583, Nov 2011

[46] K. A. M. White, S. Daneshvari, J. Lilyquist, et al., "Prediabetes: The variation between HbA1c and fasting plasma glucose," Int J Diabetol Vasc Dis Res, vol. 2015, Suppl 2: 001, Jun 2015.

[47] J. Casqueiro, J. Casqueiro, C. Alves, "Infections in patients with diabetes mellitus: A review of pathogenesis," Indian J Endocrinol Metab, vol. 16, Suppl 1, pp. S27-S36, Mar 2012.

[48] Y. H. Gan, "Host susceptibility factors to bacterial infections in type 2 diabetes," PLoS Pathog, vol. 9, no. 12, pp. e1003794, Dec 2013.

[49] D. Beran, A. Abdraimova, B. Akkazieva B, et al., "Diabetes in Kyrgyzstan: changes between 2002 and 2009," Int J Health Plan Manage, vol. 28, no. 2, pp. e121-e137, Apr-Jun 2013.

[50] K. M. Pantalone, A. D. Misra-Hebert, T. M. Hobbs, "Effect of glycemic control on the Diabetes Complications Severity Index score and development of complications in people with newly diagnosed type 2 diabetes," J Diabetes, vol. 10, no. 3, pp. 192-199, Mar 2018.

[51] P. I. Li, J. N. Wang, H. R. Guo, "A long-term quality-of-care score for predicting the occurrence of macrovascular diseases in patients with type 2 diabetes mellitus," Diabetes Res Clin Pract, vol. 139, pp. 72-80, May 2018.

[52] A. Pichon-Riviere, V. Irazola, A. Beratarrechea, et al., "Quality of life in type 2 diabetes mellitus patients requiring insulin treatment in Buenos Aires, Argentina: a cross-sectional study," Int J Health Policy Manage, vol. 4, no. 7, pp. 475-80, Apr 2015

[53] W. $\mathrm{Xu}, \mathrm{J}$. Weng, "Current role of short-term intensive insulin strategies in newly diagnosed type 2 diabetes," J Diabetes, vol. 5, no. 3, pp. 268-274, Sep 2013

[54] J. K. Dickinson, S. J. Guzman, M. D. Maryniuk, et al., "The use of language in diabetes care and education," Diabetes Care, vol. 40, no. 12, pp. 1790-1799, Dec 2017.

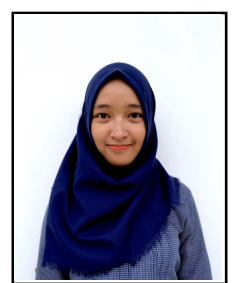

Tahira Fulazzaky was born in Bogor on 26 July 1998. She is in the final year of bachelor's degree at the Department of Biostatistics and Population Studies, Faculty of Public Health, University of Indonesia.

She was a content writing internship at Johns Hopkins Center for Communication Programs from October 2018 to December 2019. She was a research internship at Southeast Asian Ministers of Education 
Regional Center for Food and Nutrition (SEAMEO RECFON) from September 2019 to December 2019.

Since January 2018 she is a member of Global Health Initiative Indonesia for the project title of combating tuberculosis in Indonesia. Sine January 2019 she is Vice Director of Personal General Affairs at Young On Top Bogor. Since June 2019 she is Head of Information and Communication at ANALITICO of the Faculty of Public Health, University of Indonesia.

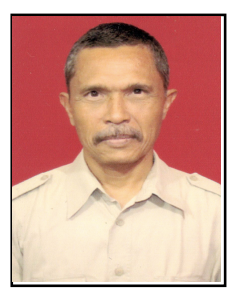

Mohamad Ali Fulazzaky was born in Pidie on 10 December 1959. He received his BSc in Chemistry in 1984 and then his Graduate degree (Sarjana) in Physical Chemistry in 1986 from Institut Teknologi Bandung in Indonesia. He received his MEng in Water Engineering and Management from Ecole Nationale des Travaux Publics de l'Etat in 1992, then his MSc in Water Treatment and Environmental Engineering from Institut National des Sciences Appliquées de Toulouse in 1993, and then his PhD in Water Chemistry and Microbiology from Université de Pau et des Pays de l'Adour in 1996 in France.

From 1986 to 1991 he worked for Perum Jasa Tirta 1 in Malang, Indonesia, with his position as Chief of Water Quality Laboratory. From 1997 to 1999 he worked for Indonesian Ministry of Public Works with his position as Chief of Section on Water Resources Conservation for Central Region of Indonesia. From 2000 to 2001 he worked for Indonesian State Ministry of Public Works with his position as Policy Analyst on Water Quality Management and Pollution Control. Then he worked for Indonesian Ministry of Settlement and Regional Infrastructures with his positions as: (1) Director at Directorate of Hydrology from 2001 to 2002 and (2) Director at Directorate of Water Resources Conservation from 2002 to 2005. From 2005 to 2017 he worked for Indonesian Ministry of Public Works and Housing with his position as functional staff/senior advisor on water resources management.

From 1998 to 2006 he has taught in the areas of water quality, water resources planning and management, drinking water treatment, and biological wastewater treatment and worked as an inviting lecturer/ professor at Institut Teknologi Bandung, Universitas Diponogoro, Universitas Islam Sultan Agung, and Universitas Pancasila in Indonesia. From December 2006 to December 2010 he worked for Universiti Tun Hussein Onn Malaysia and held as a Professor (Associate). From December 2010 to May 2016 he worked for Universiti Teknologi Malaysia and held as a Professor. Since June 2017 he is registered as a Professor and then as Chairman of Senate at Universitas Djuanda Bogor Indonesia in 2018 and since August 2018 holds also Researcher at TDTU in Ho Chi Minh City Vietnam. 